\title{
MELATIH KEMAMPUAN MENGANALISIS LITERATUR, FORMULASI GAGASAN DAN KEMAMPUAN PRESENTASI MAHASISWA MELALUI CHEMISTRY SLAM
}

\author{
Lalu Rudyat Telly Savalas ${ }^{1}$ *, Agus Abhi Purwoko ${ }^{1}$, Yayuk Andayani ${ }^{1}$, Rahmawati \\ Rahmawati $^{1}$, Baiq Fara Dwirani Sofia ${ }^{1}$, Aruna Akbar ${ }^{1}$, Ahmad Wisnu Adi Riyanto ${ }^{1}$, Jannatin \\ 'Ardhuha ${ }^{2}$, Ermia Hidayanti' \\ ${ }^{1}$ Program Studi Pendidikan Kimia, Universitas Mataram. Jalan Majapahit No. 62 \\ Mataram, NTB 83125, Indonesia. \\ ${ }^{2}$ Program Studi Pendidikan Fisika, Universitas Mataram. Jalan Majapahit No. 62 \\ Mataram, NTB 83125, Indonesia. \\ * Corresponding Author. E-mail: telly@unram.ac.id
}

Received: 18 Februari 2022 Accepted: 19 Februari 2022 Published: 19 Februari 2022

\begin{abstract}
Abstrak
Proyek pengabdian kepada masyarakat bertema chemistry slam telah dilakukan. Chemistry slam adalah versi kimia dari Science Slam yang populeritasnya semakin meningkat. Peserta kegiatan ini adalah mahasiswa tingkat sarjana dan tidak terbatas pada mahasiswa kimia atau pendidikan kimia. Dalam kegiatan chemistry slam, peserta diminta untuk menelusuri literatur tentang topik-topik tertentu dalam kimia atau kesulitan dalam pengajaran kimia yang menyebabkan miskonsepsi atau konsepsi alternatif di kalangan siswa. Mereka selanjutnya merancang strategi pengajaran dan memfilmkan peran mereka sebagai guru yang mengajarkan topik pilihan mereka. Suatu panel ahli mereview video yang dikirimkan untuk memilih pemenang dengan presentasi dan catatan konsep terbaik. Persepsi partisipan direkam dengan kuesioner yang ditindaklanjuti dengan wawancara pendalaman. Sebagian besar peserta merespon positif kegiatan ini. Sembilan puluh persen peserta menyatakan bahwa mereka berlatih untuk menganalisis artikel ilmiah secara kritis. Delapan puluh persen peserta merasa memiliki kesempatan untuk melatih diri merumuskan ide. Selain itu, sebagian besar peserta mengakui masukan dari dewan juri bermanfaat untuk meningkatkan keterampilan presentasi mereka. Secara keseluruhan, proyek chemistry slam merupakan aktivitas yang sangat baik, terutama selama pandemi di mana motivasi belajar mendekati mahasiswa umumnya rendah.
\end{abstract}

Kata Kunci: chemistry slam, membaca kritis, formulasi gagasan, kemampuan presentasi

\section{PENDAHULUAN}

Keterbatasan dalam pelaksanaan praktikum kimia (dan mata pelajaran lainnya) di tingkat dasar (tahun pertama dan kedua perkuliahan) memiliki konsekuensi rendahnya keterampilan laboratorium siswa. Kualitas pendampingan yang dilakukan asisten selama praktikum juga patut dipertanyakan karena para asisten praktikum juga merupakan produk dari sistem yang sama. Dalam konteks yang lebih luas, keterbatasan asisten praktikum juga ditemukan pada asisten yang berasal dari tingkat pasca sarjana (Mutambuki \& Schwartz, 2018).
Fakta ini menunjukkan kurangnya pengawasan pada saat praktikum dasar, baik pada saat pelatihan asisten praktikum, maupun pada saat pelaksanaan praktikum. Kurangnya supervise dari dosen juga kerap menjadi masalah dalam praktikum. Tidak jarang praktikum dasar berjalan dalam mode 'auto-pilot' di mana semua kegiatan dikelola oleh seorang asisten laboratorium dan asisten, tanpa melibatkan dosen. Selanjutnya beban kerja dosen yang tinggi menyebabkan dosen tidak mengetahui secara pasti bagaimana praktikum dilakukan. Di sisi lain, nilai akhir praktikum yang diterima dosen pendamping tidak 
memberikan informasi yang sebenarnya tentang kemampuan lab mahasiswa.

Masalah lain yang dihadapi adalah kurangnya kemampuan mahasiswa tingkat akhir untuk mengkomunikasikan topik yang kompleks dalam bidang mereka sendiri. Pengalaman mengajar pada mahasiswa kimia dan pendidikan kimia tingkat 3 dan 4 menunjukkan bahwa tidak jarang ditemukan miskonsepsi pada mahasiswa tingkat akhir. Selain itu, tidak jarang pula dijumpai miskonsepsi dan kesulitan berkomunikasi pada mahasiswa prodi studi pendidikan kimia ketika melaksanakan praktik mengajar di sekolah menengah.

Akumulasi dari kelemahan-kelemahan di atas juga dapat ditemukan baik pada kurangnya keterampilan teknis laboratorium dalam penelitian tugas akhir, dan juga kesalahan mahasiswa untuk hal-hal dasar dari perhitungan kimia sederhana.

Dalam upaya memperbaiki keadaan di atas, tim pengusul akan melakukan dua kegiatan, yaitu lomba titrasi dan lomba chemistry slam antar mahasiswa dari berbagai himpunan kemahasiswaan di Universitas Mataram.

Melalui kegiatan ini, diharapkan mahasiswa Unram khususnya asisten praktikum serta mahasiswa tingkat akhir dari Prodi Pendidikan Kimia FKIP, Prodi Kimia FMIPA, dan prodi dengan karakteristik terkait dapat didorong untuk meningkatkan keterampilannya dalam laboratorium kimia, dan dapat meningkatkan keterampilan komunikasi mereka, terutama dalam topik kompleks dalam kimia. Di masa mendatang, kegiatan ini dapat diperluas menjadi beberapa kegiatan yang melibatkan lebih banyak pihak, misalnya chemistry slam dapat dikembangan menjadi science slam (dengan peserta yang lebih beragam), serta peserta yang tidak hanya dari Unram, tetapi juga dari kampus lain.

Science slam awalnya diadakan di Jerman pada tahun 2009 (Erlemann, 2011) dan sejak itu menjadi semakin polupar di seluruh Eropa. Tantangannya adalah para peserta mencoba melakukan cara terbaik untuk mengkomunikasikan topik khusus mereka kepada audiens umum (Davies et al., 105 C.E.). Kemudian, slam menemukan tempatnya dalam sejarah ilmu komunikasi (Könneker \& Lugger, 2013). Untuk mengakomodir peserta khusus kimia, chemistry slam pertama kali diadakan di Jena pada tahun 2015 (Gerhartz, 2015).
Di masa pandemi Covid-19 saat ini, di mana siswa dibatasi dalam banyak hal, tantangan yang ditawarkan dalam chemistry slam dapat menjadi cara alternatif untuk melibatkan mahasiswa dengan cara yang ceria, kreatif dan bermakna.

\section{METODE PELAKSANAAN}

Untuk mencapai tujuan kegiatan pengabdian masyarakat ini, tim pengusul telah melaksanakan serangkaian kegiatan yang dimodifikasi dari rencana awal, terkait dengan pandemi Covid-19 yang masih berlangsung:

1. Persiapan kegiatan chemistry slam

Pada kegiatan ini tim pengusul melakukan beberapa kegiatan yaitu: pengumpulan bahan, diskusi dan perancangan petunjuk pelaksanaan kompetisi chemistry slam. Kegiatan diskusi ini berlangsung di Laboratorium TPB Lt. 1 Kampus Unram.

2. Publikasi kompetisi chemistry slam

Pada kegiatan ini tim pengusul beserta mahasiswa berasal dari HMPS P. Kimia mengirimkan flyer dan undangan secara daring melalui jejaring himpunan mahasiswa yang ada.

3. Registrasi peserta chemistry slam Registrasi peserta chemistry slam dilakukan secara daring melalui tautan yang diberikan. Registrasi dimulai akhir bulan Oktober hingga 4 November 2020.

4. Briefing peserta kompetisi chemistry slam. Briefing kegiatan dilaksanakan secara daring pada tanggal 28 Oktober 2020 sesuai undangan google meet berikut:

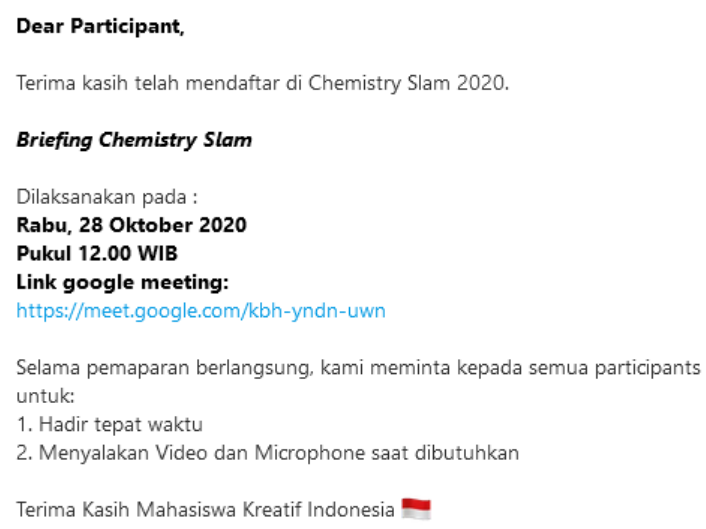

5. Masa pengunggahan video. Video pembelajaran kimia dan concept note dimulai 
setelah selesai briefing hingga tanggal 7 November 2020. Peserta yang mengirim video pembelajaran diberikan bantuan pulsa sebesar Rp. 25.000,00, setelah mereka terlebih dahulu mengisi kuissioner.

6. Penjurian

Penilaian terhadap karya video pembelajaran kimia dan naskah concept note dilakukan pada tanggal 8-10 November 2020. Penilaian dilakukan oleh pakar pembelajaran kimia yang berasal dari tim pengabdian kepada masyarakat.

7. Pengumuman pemenang beberapa ketegori kegiatan dilaksanaan secara daring pada tanggal 11 November 2020 sebagaimana undangan berikut:
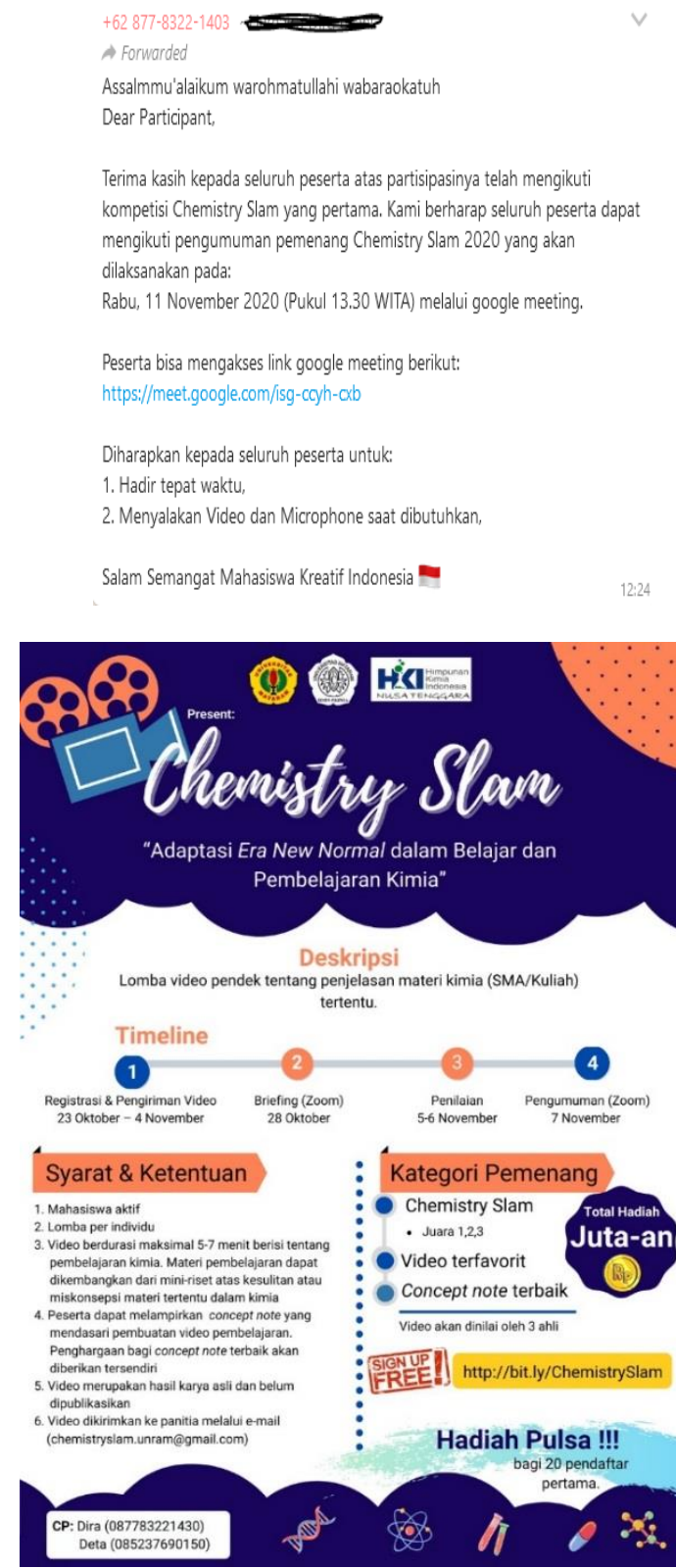

Gambar 1. Flyer Chemistry slam

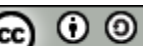

Jurnal Pengabdian Inovasi Masyarakat Indonesia is licensed under a

Creative Commons Attribution-ShareAlike 4.0 International License
8. In depth interview kepada beberapa peserta untuk mendapatkan tanggapan, persepsi, pendapat, saran dan masukan untuk perbaikan pelaksanaan kegiatan di masa mendatang (12 November -18 November 2020).

9. Pembuatan resume kegiatan, laporan akhir, registrasi seminar Pepadu dan persiapan manuskrip untuk dikirim ke jurnal ilmiah (15 November -30 November 2020).

\section{HASIL KEGIATAN}

Kegiatan chemistry slam telah dilakukan dengan peserta yang berasal dari berbagai daerah di Indonesia. Publikasi kegiatan melalui jejaring sosial terbukti efektif menarik minat peserta, sehingga peserta tidak hanya berasal dari Mataram, tetapi juga dari Sumatera, Jawa, Kalimantan hingga Sulawesi. Selain itu, latar belakang peserta tidak hanya dari program studi pendidikan kimia atau program studi kimia, melainkan juga dari program studi yang lain. Dalam situasi pandemi, kegiatan kompetisi titrasi yang direncanakan dari awal tidak dapat diselenggarakan dan kegiatan difokuskan pada chemistry slam. Kegiatan chemistry slam ini pun harus dilaksanakan secara asinkronous melalui rekaman video para peserta.

Di akhir kegiatan, setelah para pemenang diumumkan, dilakukan survey terhadap para peserta untuk menggali kesan dan masukan dari para peserta. Dari kuisioner yang diisi oleh para peserta, didapatkan hasil sebagai berikut:

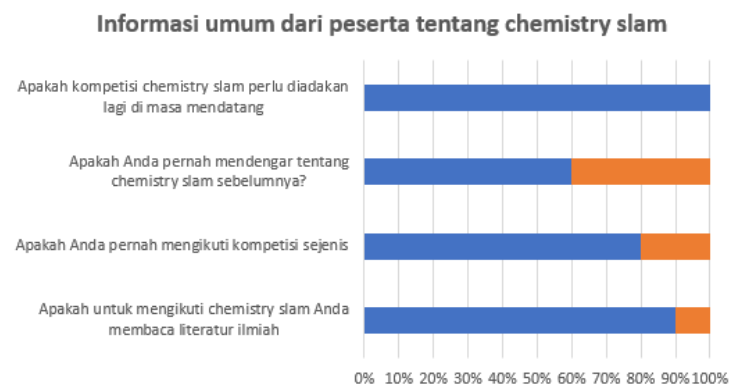

Sebagian besar peserta tidak pernah mengikuti kompetisi sejenis dan untuk mengikuti chemistry slam ini, sebagian besar peserta mendedikasikan waktu untuk menelaah literatur ilmiah sebagai referensi. Meskipun sebagian besar peserta tidak pernah mendengar kompetisi ini, setelah mengikuti kegiatan ini semua peserta menyarankan kegiatan chemistry slam diadakan lagi di masa mendatang. 
Sebagai persiapan mengikuti kompetisi ini, sebagian besar peserta menyatakan membaca dan menggunakan literatur ilmiah sebagai referensi untuk mengembangkan video pembelajaran yang akan diikutsertakan dalam lomba. Sebagian besar peserta menggunakan literatur terbaru dari jurnal ilmiah terkemuka, serta memilih dan membandingkan secara kritis literatur yang ada.

Sebagian besar peserta menuangkan isi literatur ilmiah dalam catatan-catatan dan menjelaskan kembali bagian penting dari artikel ilmiah. Analisis terhadap sikap kritis dalam membaca literatur terangkum pada hasil kuisioner berikut:

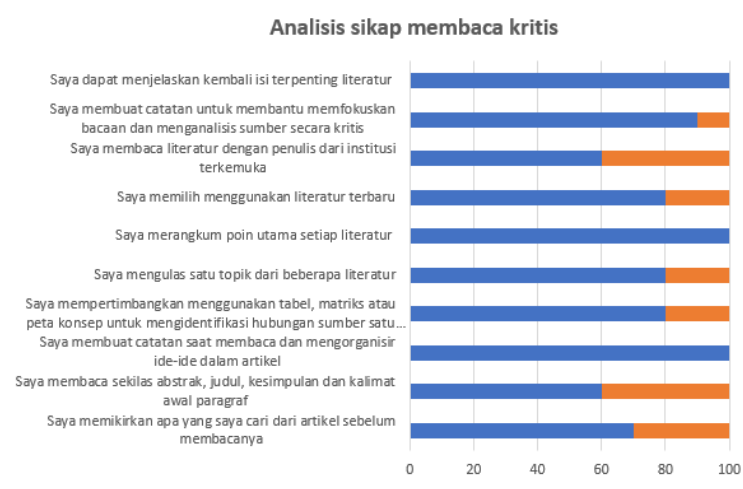

Selain penilaian terhadap video pembelajar, dalam chemistry slam juga dilombakan concept note. Hal ini mendorong sebagian besar peserta memanfaatkan studi literatur serta berusaha mengekstrak poin-poin dari literatur ilmiah dan menyusun concept note.

Sebagian besar peserta mengembangkan video pembelajaran dari literatur yang dibacanya. Dari wawancara pendalaman, terungkap bahwa peserta berusaha memaparkan konsep yang kompleks dengan bahasa yang sederhana, sebagaimana kutipan wawancara berikut:

"Ya seperti yang saya sebutkan tadi kalau dalam meramu ide itu kita harus bisa menyusun ide yang kompleks itu bisa jadi sederhana dan singkat agar orang yang mendengarkan kita itu bisa memahaminya"

Peserta lain menjelaskan lebih detil tahaptahap yang dilakukan dalam memformulasikan gagasan yang akan dituangkan dalam video pembelajaran:

"Formulating ide ya pastinya kita menyusun sebuah ide. Menyusun sebuah ide itu yang pertama kita sudah dapat referensinya, apa yang akan kita lakukan selanjutnya? Nah yang pertama kali saya lakukan itu saya memposisikan diri saya sebagai seorang yang mengalami miskonsepsi. Jadi kelihatan bahwa ketika saya cari materi-materi itu, ternyata saya sadar bahwa materi yang dasar sekali ternyata bisa salah dalam memahami. Jadi itu yang bisa saya tuangkan. Jadi pertama yang saya lakukan itu pertama tentunya mencari referensi yang terpercaya. Kedua, kita pahami konsep materinya. Kan saya mengangkat materi dasar SMA tentang ikatan kimia. Seperti yang kita tahu ikatan kimia itu ada banyak seperti ikatan ion, ikatan molekul dsb. Kemudian saya coba mengerjakan soal-soal yang berkaitan dengan materi itu. Setelah itu saya berpikir kok saya salah ya dalam mengerjakannya, kok saya mengalami miskonsepsi sih? Kemudian saya tuangkan idenya. Oh ya ternyata saya salah di bagian ini, kemudian saya cari penyelesainnya bagaiamana".

Poin-poin penting yang terkait dalam formulasi ide pengajaran yang dikembangkan selama kompetisi ini dituangkan di bawah ini:

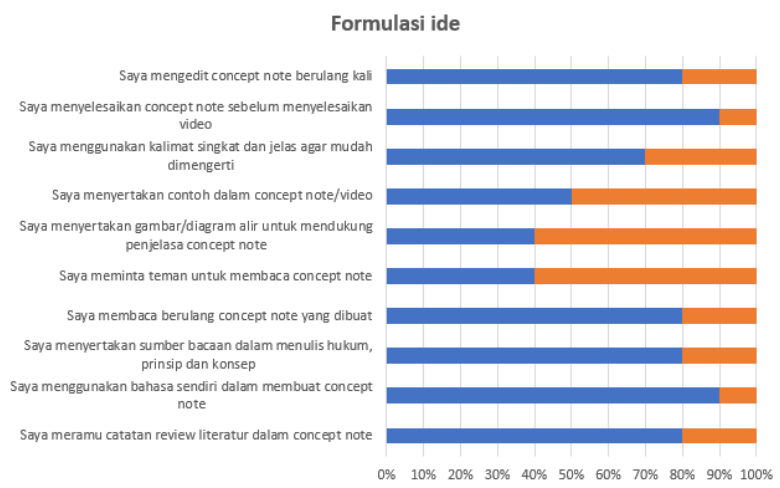

Sebagian besar peserta mempersiapkan video pembelajaran dengan memperhatikan detail tampilan powerpoint. Efek animasi dan bahasa tubuh menjadi bagian penting dalam video yang dikembangkan. Salah seorang peserta finalis mengungkapkan:

"Yang pertama pasti materi yang paling penting. Kedua, yang tidak kalah penting itu mental. Kita mampu tidak berbicara di depan audiens. Kalau pun merasa tidak bisa, apa yang bisa kita lakukan supaya kita bisa presentasi dengan baik? Ya pastinya latihan sebelum memulai presentasi. Latihan sendiri di rumah di depan kaca mungkin. Yang terakhir itu outputnya bagaimana membaut audiens itu tertarik. Nah apalagi saya ini yang sudah pengalaman banget sudah malas buat baca PPT apalagi pematerinya itu baca PPT nya sendiri. Ini yang sering terjadi. Nah bagaimana agar audiens bisa tertarik untuk 
mendengarkan presentasi tersebut? Ya harus diusahakan menarik dong, desainnya harus menarik, kemudian cara penyampaiannya semenarik mungkin, gunakan ames, ada reward dan punishment yang diberikan. Yang pastinya ga bikin audiens itu ngantuk".

Bagaimana peserta terutama finalis chemistry slam memperbaiki skil presentasi dirangkumkan dalam diagram di bawah ini:

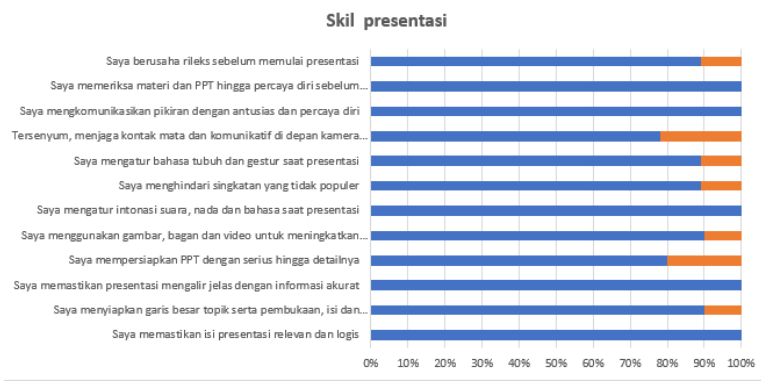

Pengaruh positif proyek lomba chemistry slam yang memanfaatkan presentasi secara asinkronous melalui video ini sejalan dengan laporan Namin dkk (Namin et al., 2021) serta Siller dkk (Siller et al., 2018). Dengan demikian, secara keseluruhan kegiatan ini memiliki banyak aspek positif dalam pembelajaran mahasiswa. Dalam konteks pembelajaran di kelas, kegiatan presentasi video ini juga dapat diadaptasi karena memberi pengaruh poitif, sebagaimana dilaporkan Richtie dkk (Ritchie, 2016).

\section{KESIMPULAN DAN SARAN}

Dari kegiatan pengabdian masyarakat yang telah dilakukan dapat disimpulkan bahwa lomba chemistry slam bagi mahasiswa telah memberikan kesempatan kepada peserta untuk menggali kemampuannya dalam mempraktekkan kemampuannya dalam mempresentasikan atau mempresentasikan materi-materi tertentu dalam kimia. Kemampuan ini juga didukung oleh proses studi literatur yang kritis, sehingga topik pembelajaran yang diangkat mencerminkan hasil studi literatur secara mandiri, dan digali dari pengalaman belajar. Sebagian besar peserta menyarankan agar kegiatan serupa dapat diadakan di masa mendatang dengan persiapan yang lebih matang, waktu yang cukup bagi peserta untuk mempersiapkan materi pembelajaran. Tim pengabdian masyarakat melihat perlunya mempertimbangkan kegiatan chemistry slam ini secara luring sehingga dapat dijadikan sebagai ajang belajar bersama.

\section{UCAPAN TERIMA KASIH}

Tim PKM menyampaikan terima kasih kepada Universitas Mataram yang telah mendukung kegiatan ini secara finansial melalui dana DIPA PNBP tahun 2000. Tim juga menyampaikan terima kasih kepada mitra kegiatan Himpunan Mahasiswa Pendidikan Kimia FKIP Universitas Mataram dan Himpunan Kimia Indonesia Cabang Nusa Tenggara.

\section{DAFTAR PUSTAKA}

Davies, S. R., Horst, M., \& Stengler, E. (105 C.E.). Studying Science Communication (Issue 2015).

Erlemann, M. (2011). Science Slams Innovative Wissenskommunikation? FE Berlin.

Gerhartz, W. (2015). Erster Chemistry Slam der GDCh. Chemie in Unserer Zeit, 49(6), 354-355. https://doi.org/10.1002/ciuz.201590049

Könneker, C., \& Lugger, B. (2013). Public Science 2.0 - Back to the future. Science, 342(6154), 49-50. https://doi.org/10.1126/science.1245848

Mutambuki, J. M., \& Schwartz, R. (2018). We don't get any training: the impact of a professional development model on teaching practices of chemistry and biology graduate teaching assistants. Chemistry Education Research and Practice, 19(1), 106-121. https://doi.org/10.1039/C7RP00133A

Namin, A., Ketron, S. C., Kaltcheva, V. D., \& Winsor, R. D. (2021). Improving Student Presentation Skills Using Asynchronous Video-Based Projects. Journal of Management Education, 45(6), 987-1010. https://doi.org/10.1177/1052562920978805

Ritchie, S. M. (2016). Self-assessment of videorecorded presentations: Does it improve skills? Active Learning in Higher Education, 17(3), 207-221. https://doi.org/10.1177/1469787416654807

Siller, T. J., Maciejewski, A. A., Leland, A. M., 
Jurnal Pengabdian Inovasi Masyarakat Indonesia, 1 (1), 2022 - 38

Savalas, Purwoko, Andayani, Rahmawati, Sofia, Akbar, Riyanto, 'Ardhuha, Hidayanti

Chen, T., Notaros, B. M., Roy, S., \& Hicks, A. C. (2018). Using student video presentations to develop communication skills. ASEE Annual Conference and
Exposition, Conference Proceedings, 2018-June. https://doi.org/10.18260/1-2-31212 